\title{
Prosthetic Rehabilitation of Patient with Anterior Segmental Mandibulectomy Using Cast Partial Removable Denture: A Clinical Report
}

\author{
Maharjan $\mathrm{A}^{1}$, Joshi $\mathrm{SP}^{2}$, Shrestha $\mathrm{P}^{3}$ \\ ${ }^{1}$ PG Resident, Department of Prosthodontics, National Academy of Medical Sciences, Bir Hospital, Kathmandu \\ ${ }^{2}$ Professor, Department of Prosthodontics, National Academy of Medical Sciences, Bir Hospital, Kathmandu \\ ${ }^{3}$ Tutor, Department of Prosthodontics, National Academy of Medical Sciences, Bir Hospital, Kathmandu
}

\begin{abstract}
Marginal mandibulectomy involves resection of mandibular body with overlying soft tissues while maintaining inferior cortex of mandible and its continuity. It may lead to numerous problems associated with mastication, speech and deglutition and esthetics. Problems associated with such defect depend upon location and extent of surgical resection. Prosthodontic rehabilitation of such patient poses challenges because of obliterated vestibular depth, inadequate denture bearing areas for support, lesser number of remaining teeth. This article describes rehabilitation of patient who underwent anterior segmental mandibulectomy with cast partial removable denture to replace the missing teeth and maintain esthetics
\end{abstract}

Key words: Defect, Esthetics, Marginal Mandibulectomy, Prosthodontic Rehabilitation

\section{Introduction}

$\mathrm{M}$ andibular defect can result from ablative tumor surgery, trauma, osteoradionecrosis and infection. ${ }^{1}$ These defects may cause morphological and functional deficits, which lead to numerous problems associated with mastication, speech and deglutition, esthetic and social problems. ${ }^{2-3}$ Problems associated with such defect depend upon location and extent of surgical resection. ${ }^{4}$ These defect present challenges to prosthetic rehabilitation because of obliterated vestibular depth, reduction in stability for prosthesis supported by soft tissue, loss of load bearing areas available for support. Anterior defects are more difficult to treat prosthodontically than

Conflict of Interest: No

*Corresponding Author
Dr.Anil Maharjan
PG Resident
Deparetment of Prosthodontics
National Academy of Medical Sciences, Bir Hospital,
Kathmandu
E-mail: anilmhj14@gmail.com

posterior due to loss of key muscle attachments (Genioglossus, Geniohyoid) located in anterior mandible that control tongue function and mobility. ${ }^{5}$ Marginal mandibulectomy involves resection of mandibular body with overlying soft tissues while maintaining inferior cortex of mandible and its continuity. ${ }^{6}$ Local and pedicle flaps are usually used for closing such defect, but they are poor prosthesis bearing surfaces due to their bulk and may impinge upon space needed for dentition. ${ }^{5}$ This article describes rehabilitation of patient who underwent anterior segmental mandibulectomy with cast partial removable denture to replace the missing teeth and maintain esthetics.

\section{Case Report}

A 65 years old patient was referred to Department of Prosthodontics, National Academy of Medical Science, Bir Hospital for prosthetic rehabilitation after anterior segemental mandibulectomy. Radiographic and histopathological evaluation revealed Ameloblastoma of anterior mandible for which 
he had undergone segmental mandibulectomy followed by reconstruction with iliac crest graft 3 years back.

Extraoral examination revealed facial asymmetry and decreased lip support in anterior mandibular region (Fig 1). Intraoral examination showed fully dentate maxillary arch, decreased depth of labial and lingual vestibule in mandibular anterior region, remaining teeth 34-37, 46-48 in lower arch (Fig 2). Occlusion of the patient was found to be satisfactory. Panoramic radiograph revealed segmental resection of mandible extending from left canine to right second premolar with good periodontal condition of remaining teeth (Fig 3).

Maxillary and mandibular primary impression were made with irreversible hydrocolloid, diagnostic casts were poured in type III dental stone and surveyed (Fig 4).

\section{Design of Cast partial denture}

Direct retainers, embrasure clasp placed in embrasure $36 \& 37,46 \& 47$, direct retainer and distal occlusal rest on 34 , lingual bar major connector was modified to adapt over crest of ridge instead of using it in anterior lingual vestibular region because of obliterated sulcus (Fig 5).

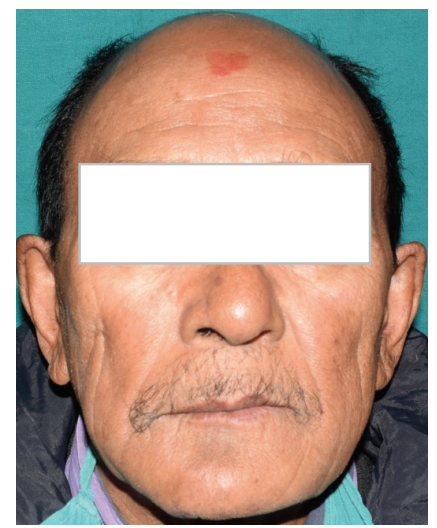

Figure 1: Extraoral View
Mouth preparation was done and final impression was made in acrylic resin custom tray using addition silicon with single step technique (Fig 6). Master cast was obtained in Type IV dental stone.

Wax pattern was fabricated according to proposed design (Fig 7). Metal try in of framework was carried out to verify its fit (Fig 8). A wax occlusion rim was adjusted to achieve tentative occlusal vertical dimension and lip support. Facebow transfer and registration of centric relation were carried out and casts were articulated in semi-adjustable articulator (Fig 9). Teeth arrangement and try in of waxed trial denture was done to evaluate denture stability, esthetics, occlusion and speech (Fig 10). Then the trial denture was processed in heat cure acrylic resin, finished, polished and delivered to the patient (Fig 11). Fig 12 shows the extraoral Photograph before and after insertion of prosthesis. Post instructions regarding routine hygiene maintainace of oral cavity and denture were given.

\section{Follow up Visits}

Patient was recalled after 24 hours to reevaluate the tissues for any trauma and check for any occlusal errors. Minor adjustment was done. Patient was recalled periodically for evaluation.

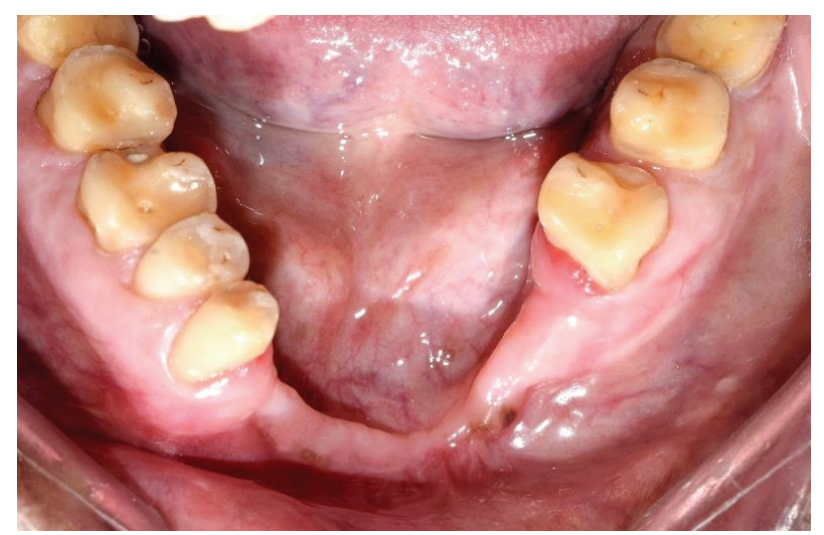

Figure 2: Intraoral Occlusal View 


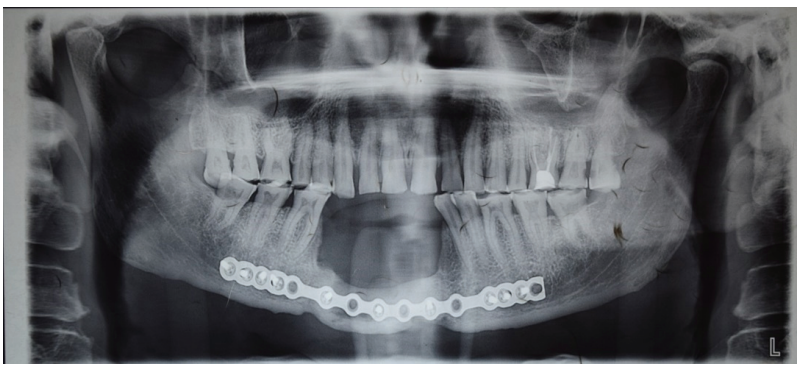

Figure 3: Panoramic Radiograph

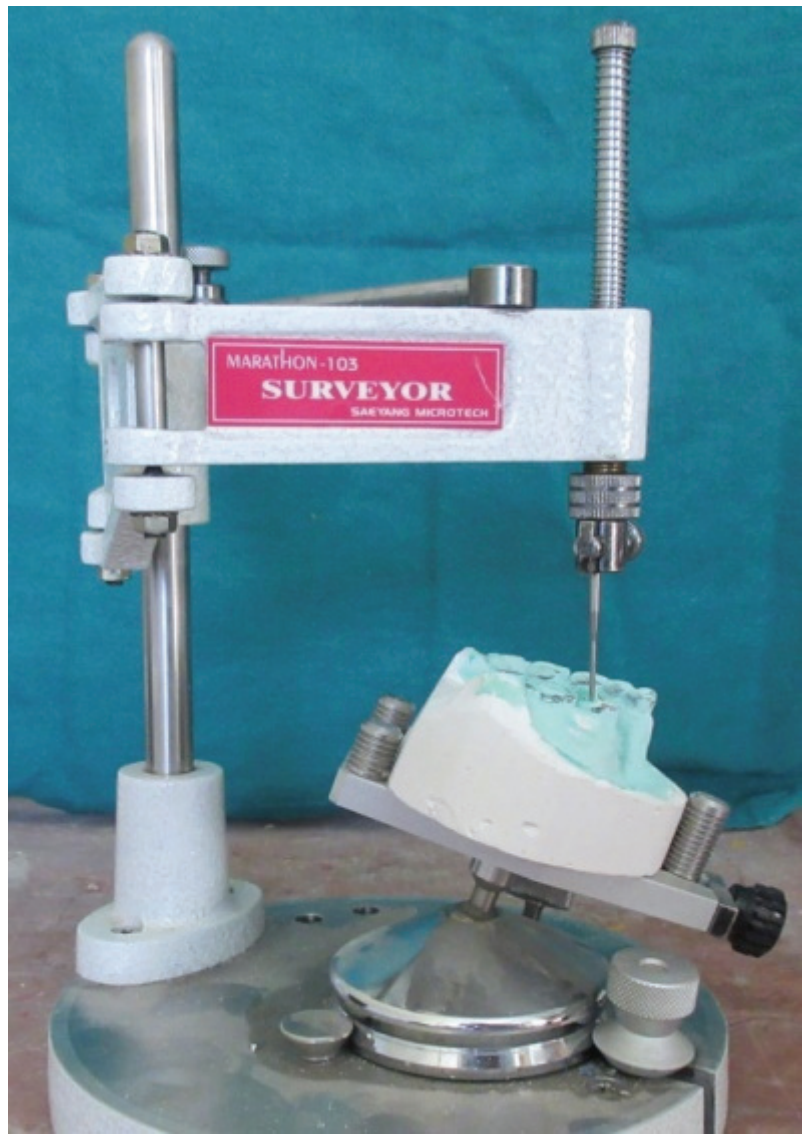

Figure 4: Surveying

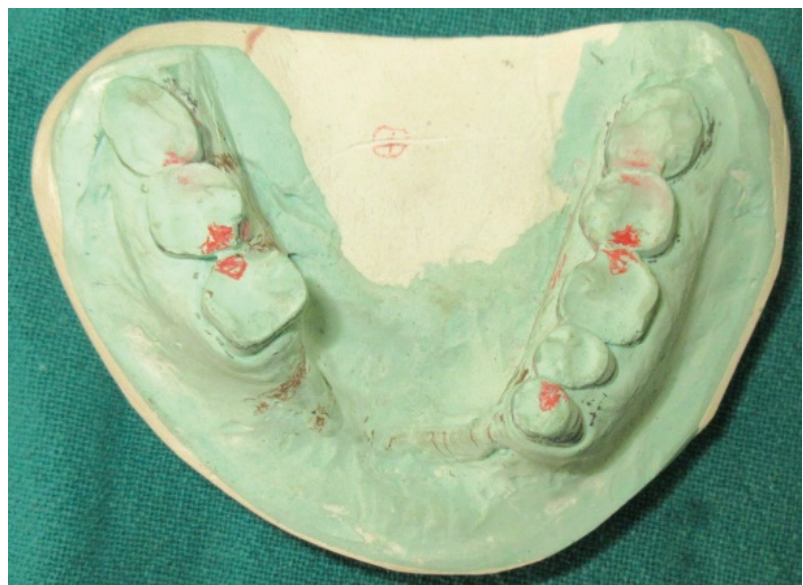

Figure 5: Proposed Design of CPD

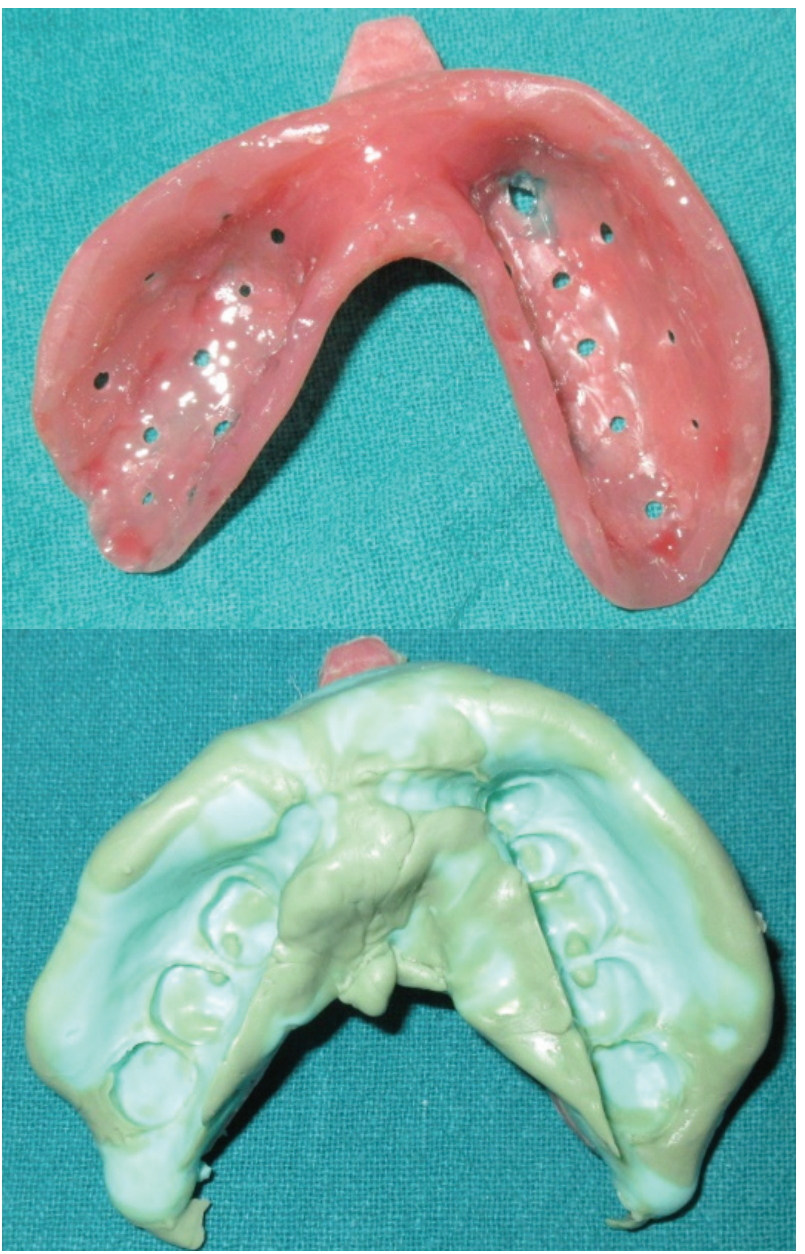

Figure 6: Final Impression

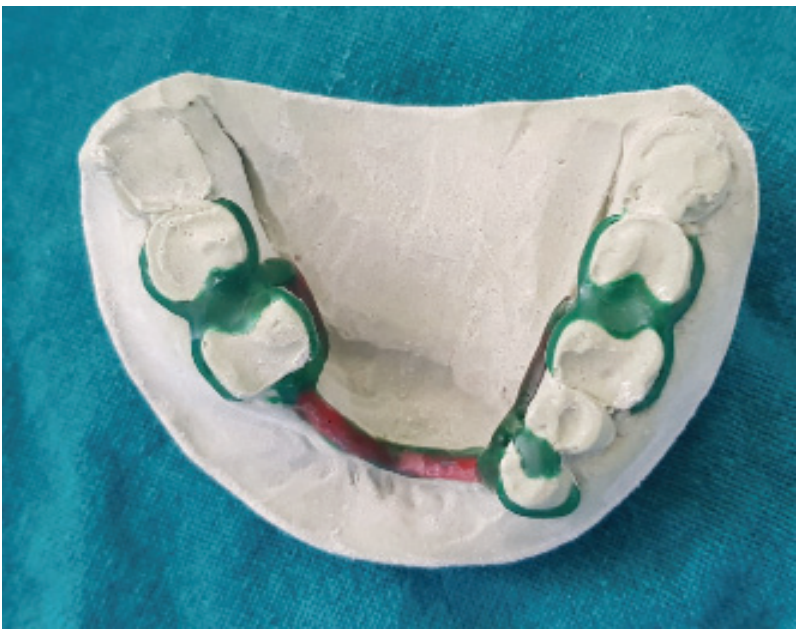

Figure 7: Wax Pattern of CPD 


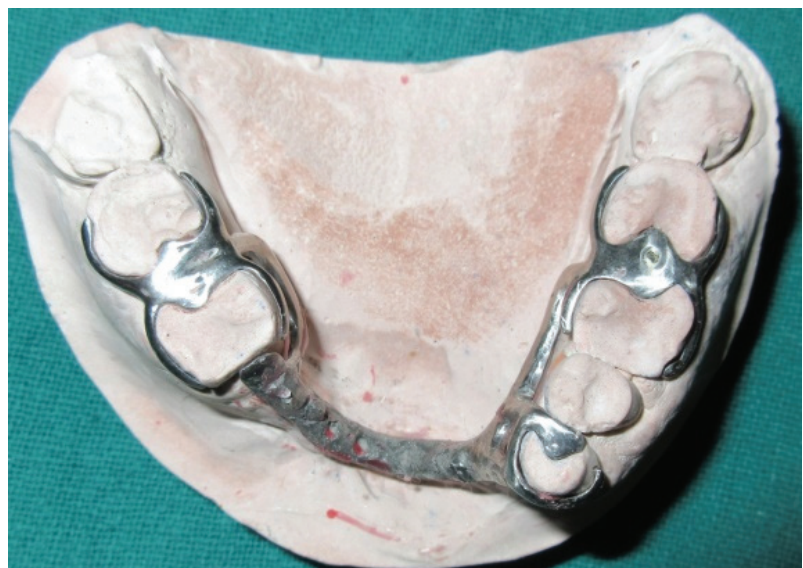

Figure 8: Metal Framework

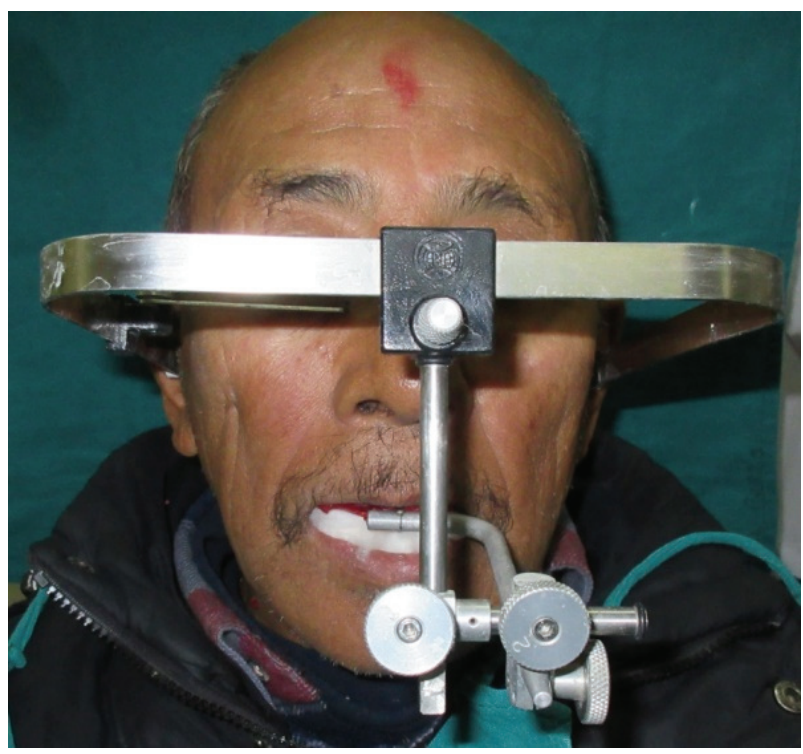

Figure 9: Facebow Transfer

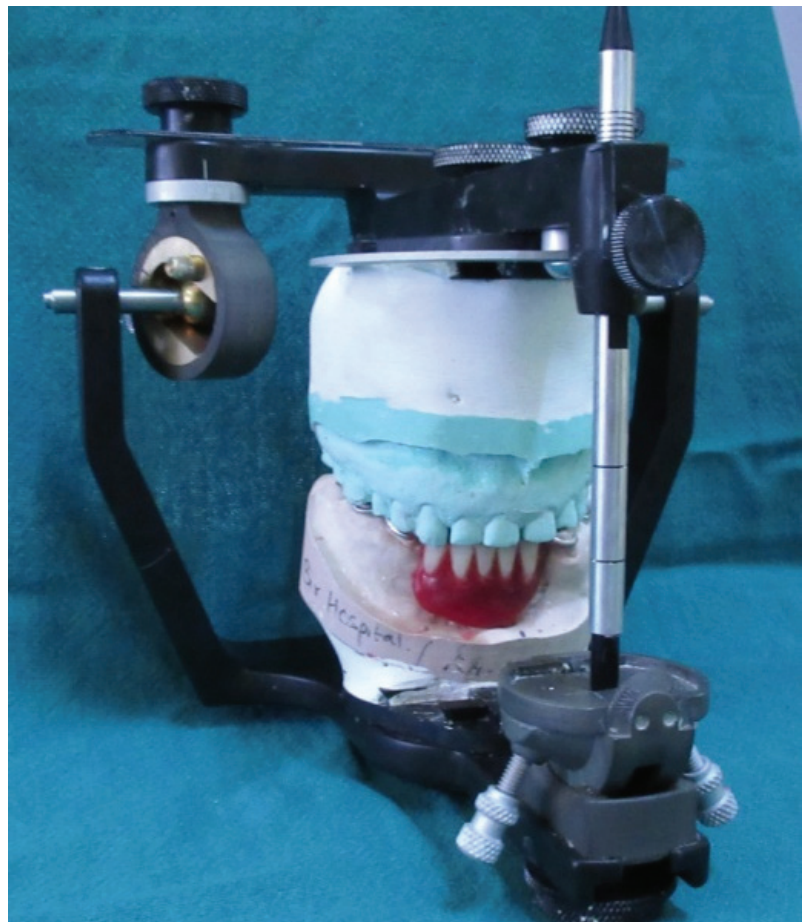

Figure 10: Teeth Arrangement
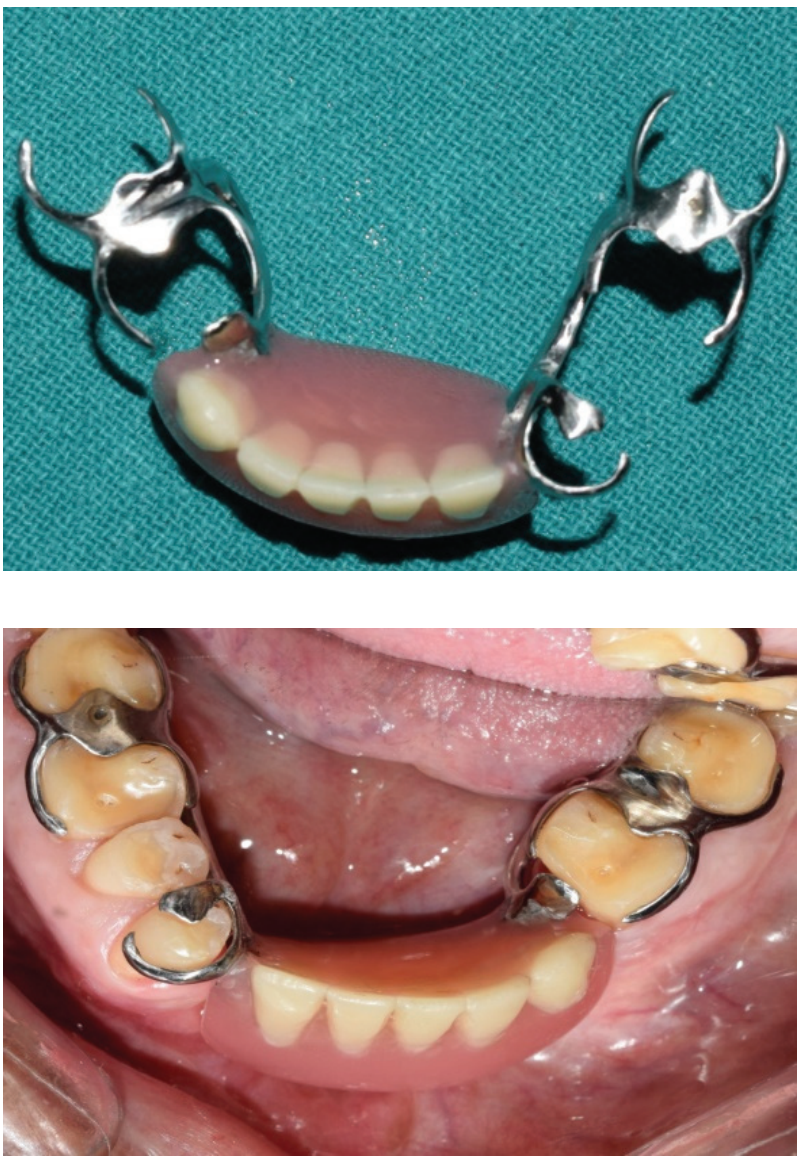

Figure 11: Insertion of CPD

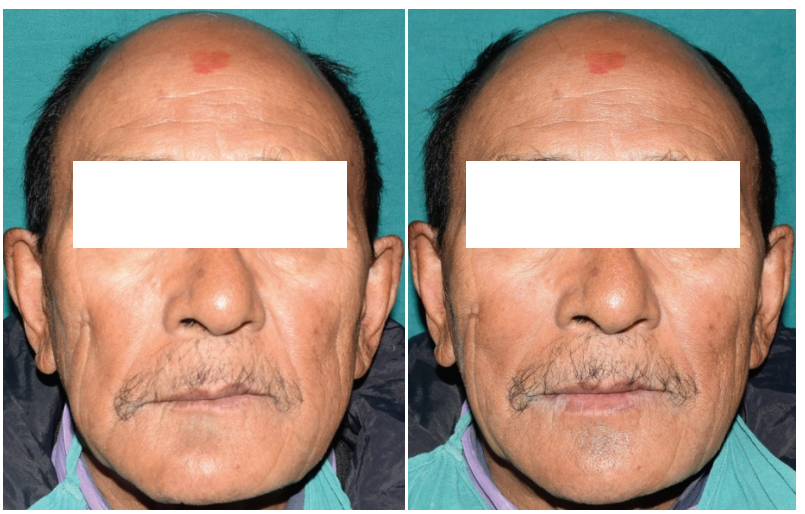

Figure 12: Before and after insertion of CPD

\section{Discussion}

Surgical resection of mandibular defects may lead to problems associated with mastication, esthetics and speech. Rehabilitation of anterior mandibular defect is difficult due to loss of key muscle attachment, curvature of mandible, inadequate denture bearing areas for support, lesser number of remaining teeth. Although 
dental implant supported prosthesis are widely used, their functional efficiency and treatment success rates have not been well established in patient with mandibulectomy.

Basic principles of clasp design should be followed. Properly designed cast partial denture helps to reduce stresses transmitted to remaining abutment teeth, maintain adequate retention. There should be harmonious occlusion with no interference in centric and eccentric movement.

\section{Conclusion}

Rehabilitation of mandibular defect depends upon extent and location of defect. Rehabilitation with cast partial removable denture with properly planned design can be one of the treatment options. It is one of the cost effective, less invasive methods to replace the missing teeth and restore lip support in anterior mandibular region.

\section{References}

1. Haller JR, Sullivan MJ. Contemporary techniques of mandibular reconstruction. Am J Otolaryngol. 1995;16:19-23

2. Beumer J, Curtis TA, Marunick MT. Maxillofacial rehabilitation: prosthodontic and surgical considerations. 1st ed. St. Louis: Ishiyaku EuroAmerica; 1996. p. 113-223.

3. Tan Z, Lui B, Wei JX, Zou H, Zhao Y. Effects of mandibular odontogenic keratocyst surgery and removable partial prostheses on masticatory performance. J Prosthet Dent 2007;97:107-11

4. Logemann JA, Bytell DE. Swallowing disorders in three types of head and neck surgical patients. Cancer 1979;44:1095-105

5. Mundhe K, Pruthi G, Jain V. Prosthodontic rehabilitation of patient with marginal mandibular resection using attachment supported prostheses: A clinical report. Contemporary Clinical Dentistry. 2014;5(1)

6. Jacob RF. Prosthodontic rehabilitation of mandibulectomy patient.In: Taylor TD, editor. Clinical Maxillofacial Prosthetics. Illinois: Quintessence Publishing Co. Inc.; 2000. p. 17188 